\title{
Effects of Melatonin on Fetal Growth and Development of
}

\section{Dairy Cows}

\author{
De Sousa AP* \\ University of Florida, USA
}

*Corresponding author: Ariane Pereira De Sousa, University of Florida, USA, Email:

sousa.ariane@ufl.edu

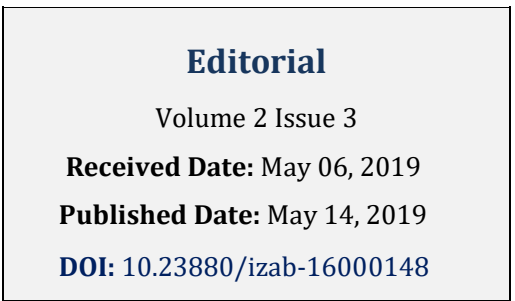

\section{Editorial}

As the dairy industry improved in technology during the twentieth century, animals were affected by a higher exposure to artificial light at night and this kind of light is comparable with a solar day light. This change in farm management brought damaging consequences to the animals, for example, a reduced production of melatonin in the pineal gland [1]. Melatonin is a hormone with a higher secretion in darkness and lower secretion during exposure to light [2]. It plays a role in the regulation of the circadian rhythm of several biological functions like heart rate and sleep-wake cycle, modulates reproduction, the neuroendocrine system, pregnancy and parturition times, CL function and it is considered an effective antioxidant $[2,3]$. In mammals, melatonin is produced by pinealocytes, retina and the gastrointestinal tract (GI). The major source of melatonin emanates from the pineal gland, and functions as an endocrine hormone [4].

During gestation, fetal growth and development can be affected by genetic, epigenetic, maternal and environmental factors [5]. Fetal growth restriction can result in everlasting restriction of post-natal growth, decreased feed efficiency and affect the body composition negatively which will lead later in a lesser quality of meat, as well as long-term deficiencies on health and athletic performance [6]. The uterine environment during late gestation is vital for assuring a continual delivery of sufficient oxygen and nutrients to the exponentially growing fetus [7]. Melatonin has several cardiovascular and vasodilation capabilities, which could influence blood distribution and antioxidant capacity in pregnant heifers [8]. Melatonin supplementation during pregnancy may alter uteroplacental blood flow through melatonergic receptor mediated pathways or indirectly by decreasing oxidative stress in the vascular $[9,10]$.

Studies did not show a difference of maternal dry matter intake, maternal body weight or body condition score between animals that received melatonin as a supplement and the ones that did not receive the supplement, but ipsilateral uterine artery blood flow, total uterine blood flow, total umbilical artery blood flow, cross-sectional area of the umbilical cord, and total antioxidant capacity were increased in pregnant animals supplemented with dietary melatonin $[7,9]$. Also Lemley, et al. [10] concluded that local melatonin infusion in the uterus increased umbilical and fetal aorta blood flow, whereas infusion with luzindole, a melatonergic receptor antagonist, decreased blood flow. All these studies established that melatonin supplementation during pregnancy alters uteroplacental blood flow, which can increase the growth and development of the fetus, which is important for the structure and health of the animal. Melatonin is also important to regulate circadian rhythm, growth and density of bones, and increases growth hormone release. More studies need to be done about the effects of the light time in cows in regions where there winter and night hours are more present compared to regions that summer and day hours happen more.

\section{References}

1. Reiter RJ (1993) The melatonin rhythm: both a clock and a calendar. Experientia 49(8): 654-664. 


\section{International Journal of Zoology and Animal Biology}

2. Zhdanova IV, Wang SY, Leclair OU, Danilova NP (2001) Melatonin promotes sleep-like state in zebrafish. Brain Res 903(1-2): 263-268.

3. Carrillo Vico A, Lardone PJ, Alvarez Sánchez N, Rodríguez Rodríguez A, Guerrero JM (2013) Melatonin: buffering the immune system. Int J Mol Sci 14(4): 8638-8683.

4. Wang L, Erlandsen H, Haavik J, Knappskog PM, Stevens RC (2002) Three-dimensional structure of human tryptophan hydroxylase and its implications for the biosynthesis of the neurotransmitters serotonin and melatonin. Biochemistry 41(42): 12569-12574.

5. Redmer DA, Wallace JM, Reynolds LP (2004) Effect of nutrient intake during pregnancy on fetal and placental growth and vascular development. Domest Anim Endocrinol 27(3): 199-217.

6. Du M, Wang B, Fu X, Yang Q, Zhu M J (2015) Fetal programming in meat production. Meat Sci 109: 4047.
7. Brockus KE, Hart CG, Gilfeather CL, Fleming BO, Lemley CO (2016b) Dietary melatonin alters uterine artery hemodynamics in pregnant Holstein heifers. Domest Anim Endocrinol 55: 1-10.

8. Brockus KE, Hart CG, Fleming BO, Smith T, Ward SH, et al. (2016a) Effects of Supplementing Holstein Heifers with Dietary Melatonin during Late Gestation on Growth and Cardiovascular Measurements of their Offspring. Reprod Domest Anim 51(2): 240-247.

9. Lemley CO, Meyer AM, Camacho LE, Neville TL, Newman DJ, et al. (2012) Melatonin supplementation alters uteroplacental hemodynamics and fetal development in an ovine model of intrauterine growth restriction. Am J Physiol Regul Integr Comp Physiol 302(4): R454-R467.

10. Lemley CO, Camacho LE, Vonnahme KA (2013) Uterine infusion of melatonin or melatonin receptor antagonist alters ovine feto-placental hemodynamics during midgestation. Biol Reprod 89(2): 40. 